\title{
Theorising practices of Relational Working across the boundaries of higher education
}

Catherine Hasted and Brett Bligh

\section{Abstract}

Higher education research is replete with discussion of boundaries imagined as structural constraints in need of removal or circumvention. But, while foregrounding national-transnational frameworks, leadership strategising, and institutional structures, the scholarship is subdued about how boundaries are actually dealt with at ground level. How do practitioners come together, day by day, across higher education boundaries; and what is required for desirable practices to be nurtured? It is on this issue, and in particular the theorisation of this issue, that the present chapter will focus.

The chapter presents and develops a relational working framework, based on the work of Anne Edwards. We highlight three core concepts (common knowledge, relational expertise and relational agency), disaggregating each into constituent features. We then apply the framework to re-interpret previously published empirical studies, to demonstrate its broad applicability. We argue that the framework usefully conceptualises how practitioners work with others across boundaries; that it helps us to notice how many boundaries are, in fact routinely permeated; and that it usefully highlights important aspects of local practices that are easily obscured.

\section{Keywords:}

Relational working; boundary crossing; higher education; boundaries; research agendas.

\section{Introduction}

Examine how university institutions are discussed in policy and mass media debates, and before long you will come across an iconic pejorative: the 'Ivory Tower'. In this telling, universities are strongly bounded, separated from the 'real' world, and grossly deficient—lacking adequate engagement with societal problems, political 
stakeholders, diverse student demographics, market pressures, economic development plans, and research commercialisation (Bok, 1982; Georgalakis, 2017).

The 'Ivory Tower' concept is but one example of how higher education 'boundedness' is vilified, with not only institutional perimeters but also 'internal' boundaries coming under fire. Academic disciplines, for example, are seen as prim guardians of inert knowledge production (cf. Spelt et al., 2009), while 'siloed' campuses are criticised for restricting the flourishing of student communities (cf. Bligh, 2019). Negative value judgements are pervasive: 'boundedness' is deeprooted, systemic, and problematic; and overcoming it is a priority concern-for 'consumers', employees, policymakers, institutions, and the sector as a whole.

Against this backdrop, what we might call a boundary-crossing agenda has increasingly suffused academic scholarship on higher education. Correctly highlighting the need to better understand existing boundaries' manifestations and implications, predominant scholarly narratives are, like their popularly-oriented counterparts, predictably normative: particular boundary types-cognitive, physical, organisational, geographical, technological (Teichler, 2000)—are positioned as troublesome; solutions are proposed, typically involving their permeation, circumnavigation or forceful removal; aspirations to replicate those solutions elsewhere are implied.

Our aim, in writing this chapter, is to resource the emergence of a different narrative: one recognising and comprehending the relational working already happening across higher education boundaries. Our ontological contention, by contrast with the above picture, is that higher education boundaries are routinely permeated by many practitioners, uncelebrated, in everyday practice. From that contention we infer two epistemological principles: that it is valuable to understand what enables those practitioners to do so; and that the absence of a common analytical vocabulary restricts that understanding. For us, the concept of relational working-based on work by Edwards (2017) — provides a suitable starting point for formulating such a vocabulary, one whose utility we wish to explore. 
Relational working, Edwards (2010) acknowledges, occurs across boundaries"social constructions" occurring where different communication-, meaning-, valueand time-systems meet (p.41). Indeed, it utilises those boundaries, bringing resources together to expand how tasks are understood. But, Edwards argues, analysing boundaries themselves is insufficient, and too often occludes "the spaces at the boundaries where the intersection of practices actually occurs" (p.41). Edwards (2010) advocates a "relational turn in expertise", attending to not only (infra)structures, boundaries, practices and subjectivity, but also the complex relations between them. Edwards suggests the necessity of understanding how relational working occurs in different ways; including where structurally sanctioned or where responding to the failure of top-down approaches ( $p .43)$.

In this chapter, we scrutinise how practitioners work relationally with others across higher education boundaries. We outline a theoretical vocabulary that, we contend, can usefully illuminate how work across boundaries is accomplished in practice. Subsequently, we apply that vocabulary to re-conceptualise findings from a disparate range of published, empirical papers that examine higher education boundary-work. The exercise provides an immediate opportunity to highlight aspects of practice that existing analyses downplay. Yet we do not suggest that relational working is normatively 'better'; all theoretical frameworks, including relational working, are partial, serving both to highlight and obscure. Our intention, instead, is initially to highlight different and useful interpretations of phenomena.

More ambitiously, we also wish cumulatively to demonstrate the value of those different interpretations: how our use of the same vocabulary to analyse ostensibly separate phenomena can highlight conceptual links obscured or fragmented in current scholarship. What, we thus explore, might be the benefits of an alternative relational working agenda for higher education research?

\section{Relational Working theory}

Pioneered by Anne Edwards $(2005 ; 2009 ; 2010 ; 2011 ; 2017)$ in a series of projects focussed on school-community links, collaboration across Children's Services, and interprofessional working in healthcare, relational working has been imported into 
higher education scholarship only recently (Hasted, 2019). Undergirded by Activity Theory, Edwards (2005) defines relational working as the 'basis of a conceptual framework to explore the relational aspects of knowledge work at the boundaries of intersecting practices' (Guile, 2011, p.59). Atypically for Activity Theory approaches, the focus of interest is primarily on subjects - the people involved and the forms of expertise they develop and mobilise.

Edwards (2017) suggests that understanding relational working involves interrogating three core concepts, which together highlight the core issues at play if ground-level collaboration across practice boundaries is to occur (p.8):

- Common knowledge: how the different motives of those involved are mediated;

- Relational expertise: how the problem posed is jointly interpreted by those involved; and

- Relational agency: how those involved align their action.

Importantly, the concepts are interrelated and dialogic in nature (Hopwood, 2017) mutual dependencies in their written formulation deliberately reflect how the abilities they describe arise, within practice, in mutually reinforcing ways.

Some time ago, we wished to understand how people came to work together within a particular research-intervention (see Hasted, 2019). Our initial attempts to apply relational working concepts stymied by the fragmented nature of their discussion across Edwards' oeuvre, we worked to condense relevant discussions into a single framework, based on an exegesis of Edwards' writings. That condensed version, hereafter called the relational working framework, forms the basis of our subsequent exposition.

Our relational working framework also augments Edwards' work in two ways. Firstly, we more explicitly delineate the specific features comprising common knowledge, relational expertise, and relational agency. Edwards does occasionally discuss that issue: for example, discussing 'features of boundary practices' as 'foundations' of 
common knowledge (2010, pp.44-45). Yet we enumerate those 'foundations' more systematically and deploy the term features more definitely: referring to distinctive attributes collectively necessary where common knowledge, relational expertise, or relational agency are achieved. Secondly, we broaden the scope of the subjects we conceive as engaged in relational working. While Edwards' mainly concentrates on service providers, others have expanded that focus to emphasise relational working with service users (Hopwood, 2017). We concur with that interpretation, especially since demarcating 'service user' identities (cf. 'students-as-consumers') in higher education is contentious. Thus, while the direct quotations we reproduce from Edwards might use terms such as practitioners, our own formulations will deliberately emphasise subjects.

\section{Common knowledge}

Edwards presents common knowledge as the bedrock for cultivating relational working. In keeping with the emphasis on subjects, Edwards (2017) defines common knowledge as subjects' knowledge about each other-their 'respectful understanding of different professional motives' (p.9). Nurturing knowledge about motives creates a powerful resource for collaboration. Yet Activity Theory highlights that motivation, counterintuitively, has external, situated origins (cf. Leontyev, 1977/2009). To some extent, therefore, understanding the motives of some subject implicitly but necessarily involves comprehending the social situation within which they undertake their labour (cf. the vernacular saying: "I can see where you are coming from").

Our relational working framework draws attention to five features of common knowledge (cf. Edwards et al., 2009; Edwards, 2010, pp.44-45):

- Knowledge of own value: how subjects reflect on their historicallyaccumulated expertise and values.

- Knowledge of others' value: how subjects develop awareness of the need to work relationally and strive to become responsive to doing so.

- Knowledge of intelligible expression: how subjects make their motives explicit and accessible to others, becoming more 'professionally multi-lingual' (Edwards, 2010, p.44). 
- Knowledge of shared purposes: how subjects recognise shared motives and deploy that recognition when collaborating.

- Knowledge of purposes: subjects' understanding of how others' motives influence their interpretation of the problem being confronted.

Importantly, since common knowledge is the ability to develop recognition of motives to undergird future working (Edwards, 2011), it requires particular conditions to develop and establish (Edwards, 2017). Firstly, since it emerges within practice, rather than springing into existence fully-formed, common knowledge requires time to become established. Secondly, since it is a mediating resource for collaborative action, there is a need for active engagement at the intersection of practices. Common knowledge is not a synonym for hybridising roles or a vehicle for organisational 'rationalisation', but instead invokes dynamic interactions centred on shared, common objects of activity. Thus, common knowledge will likely develop alongside relational expertise - the capacity for the joint engagement of subjects with particular objects.

\section{Relational expertise}

Relational expertise is defined by Edwards (2017) as follows:

A capacity to work relationally with others on complex problems. Crucially, it involves the joint interpretation of the problem as well as the joint response. The object of activity needs to be collectively expanded to reveal as much of the complexity as possible. (p.8)

Relational expertise is thus a distinct capacity mediated by a shared, complex problem; or, in other words, relations between subjects as mediated by some object of activity. Relational expertise extends beyond practitioner-specific (or disciplinary) forms of expertise, while drawing on them as antecedents.

Our relational working framework highlights three features of relational expertise (cf. Edwards, 2017, pp.8-9): 
- Capacity to interconnect expertise: how subjects relate subjects' different expertise (i.e., their own and others') to the complex problem—recognising their different applicability.

- Capacity to contextualise motives: how subjects relate subjects' motives and values to the complex problem.

- Capacity to align motives: how subjects interpret the complex problem in light of subjects' different motives when formulating a response.

The contextualisation and alignment of motives might be understood as closely analogous capacities with different directionality_proceeding, respectively, from common knowledge and from unfolding interpretations of the object (the relational working 'problem'). Like common knowledge, relational expertise is nurtured over time. The fact that its features are each related to the object means that relational expertise develops as subjects come to understand that object through their actions-in other words, it develops alongside relational agency.

\section{Relational agency}

Relational agency is defined by Edwards (2005) as:

A capacity to align one's thoughts and actions with those of others, in order to interpret problems of practice and to respond to those interpretations. (pp.169-170)

Relational agency, therefore, is fundamentally about relationships between subjects and actions-the subordinate units, regulated by specific goals, into which broader activities are disaggregated so that they can be concretely pursued by subjects in time-bounded ways. In other words, relational agency concerns how subjects align, exert, and advocate as relational working unfolds and they must repeatedly grapple with questions of "how?".

Our reading of Edwards (2010, p.62, p.91) suggests the following features: 
- Engagement of shared responsibility: how subjects negotiate and enact mutual responsibility for interpreting and responding to problems.

- Engagement of mutual support: how subjects offer and accept support from others to pursue goals.

- Engagement of coordinated action: how subjects understand what enacting change involves and means for those engaged in it.

- Engagement of flexible responses: how subjects deviate from standardised practice in response to contradictions in activity—bending rules, procedures, and hierarchy relations.

This interpretation of relational working is the one we shall apply in the next section.

\section{Theory application}

In this section we apply the relational working framework to re-interpret published empirical studies. Each investigates, in different ways, collaboration across higher education boundaries; yet none, as originally published, uses relational working concepts. Our intention is to engage with how boundary-crossing practices are prominently conceptualised within higher education, and to consider how the relational working framework might highlight different understandings.

We examine four distinct clusters of papers, each attending to different research objects-respectively, leading in a changing environment, producing societal knowledge, collaborating with industry, and negotiating intra-institutional identities. Those clusters were chosen for their spread across higher education research. Consider, for example, Tight's (2019) typology of the field (p.10). Leading in a changing environment is a 'boundary' issue in Tight's category 'institutional management'; likewise, producing societal knowledge in 'knowledge and research'; collaborating with industry in 'quality' (particularly regarding ranking); and negotiating intra-institutional identities in both 'academic work' and 'the student experience' (we analyse examples, below, relevant to both). The clusters were also selected for conceptual variety, allowing us to demonstrate our framework's flexibility and utility in critically re-analysing work presented using concepts derived, respectively, from 
distributed and boundary-spanning leadership; Mode 2 knowledge production; Communities of Practice and Activity Theory; and Bourdieusian and Butlerian practice theories. In each case, we examine the extent to which selected papers recognise issues corresponding to the three main concepts of relational working, and highlight some of the specific analytical features implicated, using the terminology introduced above.

\section{Leading in a changing environment}

The first cluster of work we scrutinise investigates the enhanced leadership practices required where higher education boundaries are perforated. We examine two papers, chosen firstly, to reflect the emphasis on 'distributed' leadership in contemporary scholarship; secondly, because each is commendably explicit about its theoretical basis; and, thirdly, because each appears in a core higher education research venue (respectively, Higher Education Research \& Development and Studies in Higher Education).

Each paper takes the changing environment in which universities operate as their departure point. For Prysor and Henley, (2018, p.2210), a "perfect storm of external challenges and pressures"-changing regulatory environments, updated business models, internationalisation, external engagement, knowledge exchange, the impact of disruptive technologies-is radically broadening the range of leadership skills required across the sector. Likewise, for Sewerin and Holmberg (2017), the attendant "[r]eform initiatives in institutions of higher education and research currently emphasize the role of leaders as a key element for implementing change" (p.1281, our emphasis).

Sewerin and Holmberg (2017) wish to suggest that higher education leadership will increasingly operate within multiple, contesting modes; their study, correspondingly, unpicks four "institutional logics" evident within "key activities" of a technical university in northern Europe. Prysor and Henley (2018), meanwhile, examine the "boundary-spanning" activities of institutional leaders, using as their research site a research-oriented UK university. 
Prima facie, the papers exhibit several argumentational similarities. Both suggest that out-of-date leadership practices, reflecting stable, silo-based structures, remain prevalent in many higher education institutions. Each reinforces a need for institutions to support more fluid forms of leadership—so leaders are better able to mobilise knowledge and resources. Both introduce an external, yet avowedly "practice-specific", theoretical frame-'boundary spanning leadership' (BSL) and 'distributed leadership', respectively_and contemplate its translocation to higher education. Furthermore, both conclude by emphasising the necessity of particular 'contextual conditions' (Sewerin and Holmberg, 2017, p.1292) for their frame's adoption into higher education. Prysor and Henley (2018), for example, highlight 'the prevalence of particular forms of boundaries that the HE leaders identify as prominent'; and the breadth and degree to which 'BSL practices' are considered and applied by leaders.

With regard to common knowledge, our reading is that the papers consider 'knowledge' extensively, but in a highly one-sided manner. Both successfully emphasise participants' perceptions of how they relate to the boundary types they are expected to act upon. Reflecting the feature we have called the knowledge of purposes, Prysor and Henley (2018) emphasise how their BSL framework steers researchers and practitioners toward understanding leadership as the collaborative engagement of expertise around 'a common cause', rather than as an atomised skillset. Yet the responsibility for understanding others (their motives, their interpretation of the problem) is positioned as a core responsibility of the 'boundaryspanning leader'. Largely absent is recognition that 'becoming responsive' to stakeholder needs might involve working with them. Whilst Prysor and Henley deliberately select study subjects who engage with internal and external 'stakeholders' (university staff, external partners, parents and students) and acknowledge that stakeholder boundaries are those 'most commonly referenced by interviewees', that engagement remains examined only from the "leader's" perspective. Sewerin and Holmberg (2017), similarly, specifically describe the perspectives of 'staff with potential for taking on more senior leader roles' (p.2383). Theoretical references to 'distributed' leadership notwithstanding, the papers' emphasis on 'leadership' seemingly encourages the analytical isolation of leaders' knowledge. 
That said, the two papers do helpfully emphasise the conditions under which common knowledge might be nurtured. For example, Prysor and Henley (2018) argue for the importance of providing time to clarify responsibilities, consider stakeholders' perspectives, and negotiate 'shared values'-echoing our earlier discussion about the nurturing of common knowledge (in this case, the knowledge of own value and knowledge of shared purposes). Yet, once again, the analytical isolation of leaders restricts how the resulting knowledge products are problematised; developing and using jointly-owned responsibilities and values, for example, goes unconsidered. A relational working approach to common knowledge would encourage a broader perspective: investigating the extent to which leaders work responsively with, and how they and their motives are understood by, other subjects—both the 'stakeholders' recognised in these papers, or other 'leaders' across some practice boundary.

The picture is also partial with regard to relational expertise. Both studies, notably, identify how successful leadership across boundaries necessarily builds on the interrelation of motives. For Sewerin and Holmberg (2017), such interrelation is axiomatic for distributed leadership, which involves:

the ability to see and acknowledge other fields, to connect and build the platform and preconditions for satisfying mutual needs. (p.1287)

Similarly, Prysor and Henley (2018) acknowledge the recognition of motives as a precursor to constructing a unifying 'group identity'. Such an interpretation, moving from elaborating common knowledge to discussing the purposes of its mobilisation, resonates with the capacity to interconnect expertise. Yet those purposes-building platforms, constructing group identity—remain specified quite generically: the object of activity is, in our view, insufficiently investigated within the papers. Consequently, neither the capacity to contextualise motives nor the capacity to align motives can be elaborated for the practice setting. For example, Prysor and Henley do convincingly identify that the leaders they studied were unable to transform practice; but, absent a concrete understanding of what those involved were trying to do, the underlying reasons remain obscure. To better understand such points of impasse, our 
framework would suggest examining leaders' capacity to align motives in relation to more concrete objects of activity.

Straightforwardly, both papers fall very short of appreciating the role of relational agency. While both recognise that the leaders they examine are skilled at building foundational knowledge (cf. common knowledge) and thus mobilising boundary working, neither analyses how that mobilisation takes place in action; their frames of enquiry, in this regard, remain static. Prysor and Henley (2018), for example, articulate their theoretical framework as a matrix of boundary practices that support a 'bridging' of relationships, rather than action and advocative behaviour. Future empirical studies interrogating relational agency in leadership practices might, therefore, contribute significantly to this domain of enquiry.

Overall, these papers seem strongest at conceptualising relational expertise: recognising leadership as institutionally embedded in networks of perspectives, while insufficiently examining the object of activity towards which those perspectives are oriented. That conception of relational expertise, in turn, builds on analytical analogues to common knowledge that usefully recognise the need to understand one's own value and shared purposes. Yet the accounts are highly partial, occluding how leaders work with the strengths of stakeholders and thus pondering apparently static relationships. In turn, relational agency (the alignment of action and advocative behaviour) gets overlooked. The relational working framework, we suggest, might underpin more dynamic investigations of how "leadership" becomes embedded within the practices of all involved subjects. Doing so might prove useful in examining those instances, highlighted in both papers, where leaders with admirable skill levels do not achieve transformational change across boundaries.

\section{Producing societal knowledge}

Our second cluster concerns "socially-responsive" research collaboration: a "more 'engaged' form of scholarship which applies itself consciously to the pursuit of applied knowledge which can contribute towards solving some of the most pressing societal challenges" (Brown-Luthango, 2013, p.309). Often previously characterised as research 'translation', a metaphor now disparaged as incorrectly unidirectional 
(Penuel et al., 2015), such work involves HE subjects striving to bridge scholarly research and practice_- "gaps between knowledge and action" (Esler et al., 2016, p.76)_-by engaging with 'real-world' practices and problems. In this regard, producing societal knowledge bears some ostensible similarity to collaborating with industry, a cluster we discuss subsequently, though, as we shall demonstrate, their different objectives and stakeholders warrant separate analysis.

We consider three papers (Brown-Luthango, 2013; Esler et al., 2016; Penuel et al., 2015), once again selected because they reflect prominent contemporary arguments while being explicit about theory. Each is motivated by a desire to break out of 'Mode 1 ' knowledge production, conceived as narrowly 'academic' and oriented towards 'disciplinary' research objects, and to foster 'Mode 2' knowledge production, oriented towards 'real-world' problem-solving (cf. Nowotny et al., 2001). Mode 2 knowledge production is positioned as necessarily collaborative, 'application-oriented', and transdisciplinary-building on disciplinary knowledge but integrating wider perspectives (Brown-Luthango, 2013). On this basis, the three papers conceptualise their research objects as a form of research collaboration and examine how knowledge moves across boundaries. The paper by Brown-Luthango is published in a core higher education research community journal (Higher Education); while the others are products of interdisciplinary research teams and presented in venues aimed at discernably 'Mode 2' audiences (such as Current Opinion in Environmental Sustainability).

Esler et al. (2016) examine an interdisciplinary training programme oriented towards social-ecological challenges in South Africa: postgraduate students and supervisors from several disciplines work alongside external stakeholders, such as the South African Water Research Commission, in eight ecological restoration projects. BrownLuthango (2013) examines an initiative, also in South Africa, wherein public engagement "CityLabs" are distributed across Cape Town, focussing mainly on one case where civil society actors in the Philippi district discuss urban planning. Penuel et al. (2015), meanwhile, study two university-school district partnerships in the southern USA: one focussed on teacher professional development, the other on mathematics education. 
Viewed through the lens of common knowledge, it is noticeable that all three papers underscore the importance of cultivating listening and questioning, thereby expanding mutual understanding as a precursor to mobilising ideas (cf. knowledge of purposes). Penuel et al. (2015), for example, characterise this as striving for the mutual recognition of participants 'across multiple boundaries' (p.182). The papers also highlight the centrality of developing respectful understanding of shared longterm values, as a basis for mediating collaboration (cf. knowledge of shared purposes). In this respect, Penuel et al. (2015) assert the importance of joint work, highlighting an example of shared, long-term 'goals' that 'are defined and evolve through interaction' (p.183). The knowledge of others' value, conversely, is underemphasised; whilst the meaning of 'practice' is deliberately interpreted widely within the studies, that is not extended so far as the engagement of researchers with 'clients'. Penuel et al. (2015), for instance, regard students as central to the research object—conceptualised as 'to meet students' needs' (p.188)—yet how practitioners strive to work relationally with those students is not highlighted.

Perhaps ironically, given the above caveat, the three papers otherwise implicate relational expertise (albeit, between non-'client' practitioners) more than those in any other cluster we consider. Indeed, Penuel et al. (2015) purposefully state that:

Boundary practices can also provide a means for partners to surface relevant expertise of both people in the practice and those whose expertise might be relevant, but who are not currently part of the partnership. (p.193)

That assertion strongly resonates with the capacity to interconnect expertise, and the recognition of potentially related expertise not yet incorporated within boundary work is valuable. The papers also emphasise the importance of building awareness of subjective motives driving unfamiliar practices (cf. capacity to contextualise motives). Esler et al. (2016), for example, argue that:

Interdisciplinary collaboration also requires a relatively large time investment to allow for relationships to establish and for teams to evolve past initial differences in perspectives, cultures, methods, theories and approaches. (p.4) 
The papers diverge, however, in their recognition of the capacity to align motives. Brown-Luthango (2013) discusses the issue extensively, suggesting that alignment with community partners' motives is essential if university-community partnerships are to move from knowledge to practice:

This means that the aims, mode of operating and anticipated outcomes and benefits of the planned collaboration are carefully negotiated upfront and crucially, that research projects are jointly conceived and driven by both partners and not only by the needs of the university partner. (p.311)

Brown-Luthango subsequently laments the lack of such alignment in the case examined: 'there was no involvement of community members or groups in the conceptualisation of the CityLab or the setting of aims and objectives' (p.320). By contrast, the paper by Esler et al. (2016) positions their research partnership as 'student driven', and yet the fact that it was 'designed by a core leadership team' (p.82) passes largely unremarked. The partnerships' alignment with motives of student-practitioners seems worthy of further investigation. The relational working framework would, in this regard, encourage analyses to focus beyond the 'movement of knowledge', to consider how subject-subject interactions become configured.

Reading the papers through the lens of relational agency also highlights a positive, if partial, picture. All three papers recognise that socially responsive research collaborations require mutuality (or reciprocity) as a central tenet: 'mutual engagement' and 'mutual learning' in Penuel et al. (2015, pp.187, 192); 'mutually beneficial' working in Brown-Luthango (2013, p.323). Participants are understood as offering and accepting support from others when seeking to interpret and address problems of practice (cf. engagement of mutual support). The papers also highlight the engagement of coordinated action. For example, Penuel et al. (2015) positions practitioners' ability to effect change in the design of mathematics instruction as a function of their coordination. Yet the engagement of flexible responses goes unconsidered: no analytical consideration is given to shifts in patterns of working, or aberrations, within collaborations. Deploying theoretical frameworks focussing extensively on 'knowledge production' seemingly occludes, in these cases, rulebending, risk-taking and development in response to contradictions in practice. 
Overall, these papers align quite closely to relational working principles: recognising the time investment required to contextualise motives (cf. relational expertise) and strongly invoking mutuality (cf. relational agency). Yet the relational working framework still highlights prevailing lacunae. Investigating knowledge of other's value, for example, would better highlight how participants come to work with those who supposedly benefit from collaboration, and how the attendant necessity of knowledge of intelligible expression might develop. Such analysis might challenge, among other things, assumptions about the relative degrees of involvement of different subjects. Furthermore, attending to the engagement of flexible responses would enhance understanding of practice deviations and innovations emerging as relational working develops. Tracing subjects' responses to practice contradictions can highlight, in particular, the extent to which collaborators are aligning their actions or continuing to work in parallel.

\section{Collaborating with industry}

The third cluster of work we examine is, like the second, concerned with university engagement with 'real-world' objectives. Yet industry collaboration is more immediately driven by ambitions to enhance institutional prestige indicators, such as 'employability' and 'economic impact'-usually via knowledge-exchange and research commercialisation initiatives (Enders, 2005). Scholarship on the issue, in turn, typically foregrounds demonstrable commercial-economic value, problematising academic knowledge by reference to economic output implications.

We analyse three papers; once again, chosen for the visibility of their theoretical influences, their reflection of current debates, and their publication in venues contributing to appropriate communities-the higher education research field (Higher Education), specialist debates (Higher Education, Skills and Work-Based Learning) and policy issues (Science and Public Policy). Hemmert (2017) broadly surveys university researchers involved in university-industry research collaboration initiatives, analysing their perceptions of the knowledge they acquire through participating. Algers et al. (2016) document the development and implementation of a Work-Based Learning model, deployed by a university in Sweden in partnership 
with food industry organisations; their paper investigates the negotiation of project work by teachers, students, and industrial-placement supervisors. Garraway (2006), meanwhile, provides a case study of "industry responsive curriculum design", documenting the co-design of curricula across an engineering department by 'polytechnic committees'-in which "industrialists" play a leading role.

Once again, prima facie, the papers exhibit argumentational similarities. Having established an economic warrant of the kind we acknowledge above, the papers each invoke the scholarship on boundary-crossing. While variously theorisedthough often borrowing concepts from Communities of Practice or Activity Theorythe thread of commonality is an emphasis on how knowledge acquisition occurs within social nexuses. The papers each examine, correspondingly, how the performance of the industry collaboration is a function of underpinning social mechanisms, and then seek to make theoretically-derived recommendations. Garraway's (2006) paper, for example, deploys Communities of Practice concepts to argue that boundary-crossing interactions might be facilitated by nurturing 'reflective spaces, hybrid objects' and a 'pidgin language' that creates a language-in-common between distinct practices ( $p .462)$.

Straightforwardly, each paper largely elides common knowledge issues. Each paper does, to be fair, foreground the importance of respecting different professional motives-for example, university and industry partners' reciprocity and respective capacity to 'understand their partner, align their working styles and avoid misunderstandings and frictions' (Hemmert, 2017, p.202, cf. knowledge of shared purposes). Yet the accounts are tokenistic: analysis shifts quickly to other issues and does not dwell on how such reciprocity might be built-for example, how participants become fluent in making expertise explicit and accessible to others (cf. knowledge of intelligible expression). Even Garraway's comments about 'pidgin languages', which appear promising, are oriented more towards grasping common problems than subjects' knowledge of each other. Understanding the latter seems crucial for preparing practitioners for future exchanges, beyond immediate temporal and domain limitations, and so, in turn, for understanding the longer-term development of relational working with industrial partners. 
The papers do prominently highlight, conversely, issues of relational expertise. Indeed, each paper explicitly frames its research object, to some extent, as a relational expertise issue: conceiving industry collaboration as stimulated by specific, albeit complex, problems that require new expertise to be developed. Analyses, in turn, foreground how joint responses to complex problems requires recognising and aligning motives and values. For example, Garraway (2006) intentionally selects case study examples 'that engage formal purposeful interaction between work and academia', and proceeds to trace the negotiated interpretation of that interactionwhich in this example becomes honed to 'developing effective problem solvers' (Garraway, 2006, p.450). Garraway's analysis thus productively oscillates between what we have called the capacity to align motives and the capacity to contextualise motives.

Yet the picture presented remains partial: the capacity to interconnect expertise, in particular, remains occluded. Garraway's (2006) analysis actually hints that this capacity is lacking: participants are noticed simply rewording problems, and 'points are presented and recorded rather than discussed at length' (p.453). Yet the issue remains unexplored. Why do academics and industry partners (in this instance) only manage to surface the differences in their expertise in relation to certain problems? Directly examining committee members' capacity to interconnect their expertise would allow for more nuanced understanding — but would also likely require further examination of common knowledge issues which are presently, as noted above, largely avoided. As we noted in our theoretical overview, the core concepts of relational working are interrelated and dialogic; conceptually isolating relational expertise, as attempted here, inevitably germinates analytical limits.

The picture with regard to relational agency is also partial. On the one hand, the papers prominently emphasise practitioners' sense of mutual responsibility (cf. our engagement of shared responsibility). Algers et al. (2016), for example, place emphasis on 'systemic negotiations between actors from the three parties: the academy, the industry, and the students' (p.2). Shared responsibility is important for the design and flow of the Work-Based Learning programme, they argue, if it is to remain relevant to both academic and food industry concerns. Algers et al. also analyse relations between subjects' degrees of influence and their ability to control or 
contradict established procedures_-foregrounding how the engagement of flexible responses is a site of struggle, deeply influenced by power relations. Yet the engagement of mutual support (how subjects mutually offer and accept support) and the engagement of coordinated action (how partners understand what enacting change comes to mean for others) are occluded, with acute analytical consequences. Algers et al. mourn how 'students did not seem to give equal weight to the two activity systems but to gradually adapt the agenda and perspectives of the industry' (p.16). It seems that, during their internships, students acted in isolation from (some) other stakeholders, rather than sustaining relational agency. Algers et al. notice this practice problem-which our framework would locate as a function of how joint action and advocacy takes place over time and across boundaries-but seem unable to analyse it.

In summary, these papers substantially focus on issues of relational expertise, reaching theoretically sophisticated conclusions about directly attendant issues, while highlighting, correctly, the challenging nature of nurturing mutually beneficial action across boundaries. Yet the relational working framework might usefully contribute: most encompassingly, by highlighting the extent of dependency between relational expertise and both common knowledge and relational agency. More specifically, the framework would further problematise how collaborators make their expertise accessible to others (cf. capacity to interconnect expertise), and thus how relational working might plausibly be sustained beyond bounded interventions. Additionally, more systematically considering the engagement of flexible responses-nonconformity, rule-bending and risk-taking in response to practice contradictions-might highlight how subjects strive to overcome, in practice, the points of 'hiatus' (Garraway, 2006) and 'isolation' (Algers et al., 2016) that these papers highlight so prominently.

\section{Negotiating intra-institutional identities}

Our final cluster of papers focusses on boundary negotiation within institutions. We analyse two papers focussing on identity negotiation: specifically, how academics work relationally with $P h D$ students, a topic selected, as mentioned earlier, for its 
relevance to both academic work and the student experience. Once again, we select theoretically explicit papers; one published in a core higher education research journal (Studies in Higher Education), the other in a specialist venue (Educational Action Research). Petersen (2007) focusses on doctoral supervision itself, examining how PhD students become legitimate higher education subjects-their “academicity” recognised within particular discourse communities. Mahon (2017), conversely, examines how "collaborative processes" and "democratic relations" are enacted within an action research $\mathrm{PhD}$ project that facilitates academics, via groupwork, enacting critical pedagogical praxis. The papers thus have a certain symmetry: ostensibly, academics influencing PhD students, and vice versa.

Once again, the papers exhibit argumentational similarity. Motivated to analyse practice in a manner sensitive to 'existing power relations' (Mahon, 2017, p.77), each selects a theoretical framework foregrounding power and agency: respectively, Bourdieu's 'theory of practice' and Butler's 'subjection'. The key arguments in each case interrogate the complexities of fostering desirable practices-such as 'democratic participation'-and draw substantially on theoretical vocabulary to project future ideas for nurturing those practices. For example, Petersen's (2007) conclusions utilise the notion of 'mastery through subjection', and suggest further use of 'category boundary work' as an analytical tool by supervisors and supervisees to interrogate 'being academic' (pp.478-479).

The papers highlight common knowledge prominently, albeit incompletely. Both conspicuously highlight the importance of developing a shared understanding of 'acts, articulations, desires and bodies' (Petersen, 2007, p.479, cf. knowledge of purposes). Each also heavily emphasises the articulation of one's own expertise and values (cf. knowledge of own value), with acts of reflection and questioning positioned as necessary before collaboration. Petersen (2007), for example, suggests that PhD students should reflect on issues such as: 'what kind of a researcher am I; how do I need to and want to conduct my academic self?' (p.479). Mahon (2017), similarly, reflects of the subjects in her project: 'we were seeking to enhance our self-knowledge and practical wisdom' (p.75). Yet, conversely, the fact that common knowledge requires becoming 'professionally multi-lingual', making 
one's own expertise available to others (cf, knowledge of intelligible expression), is absent. That is surprising: both papers involve developing academic expertise, in a policy context where academics are 'increasingly expected to work across disciplinary and institutional divides and to work with practitioners from industry and other public and private organisations' (Enders, 2005, p.128). Better understanding how, or whether, knowledge of intelligible expression is developed would thus seem important to understanding the development of future-oriented academic identities (cf. Hasted, 2019).

Also surprising is the limited degree to which the papers highlight issues of relational expertise. Negotiating and maintaining boundaries is the stated focus of each, yet the capacity to align motives, crucial to such endeavours, goes unexamined. Admittedly, limited attention is given to viewing expertise relationally in respect of problems (cf., capacity to interconnect expertise). Petersen (2007), for example, highlights an interesting case of using external expertise to negotiate boundary tensions: a supervisor works with a colleague to jointly interpret the 'problem' of an overly-dependent doctoral student; and it is the colleague who cautions the supervisor to 'be careful of judging others by her own values and standards' (p.481). Yet relational expertise remains, overall, neglected. It seems that the selected theoretical frameworks are helpful in identifying power asymmetries, but less so for theorising how practitioners might strive to overcome such asymmetries (loc. cit., by reinterpreting apparent 'problems').

The papers, conversely, highlight relational agency very effectively-in particular, diagnosing its limited expression in the practices under examination. The engagement of flexible responses is heavily implicated in those diagnoses. Mahon (2017), for example, discusses academic group debates: existing (or prior) working is observed, with observations serving as a resource for expanding the interpretation of problems. One participant discusses how:

Sometimes I think instead of just recognising the tragedy and the contradictions, I sense also part of the critical move is to draw upon triumphs as well, where you are able to demonstrate through cases. (p.78) 
Petersen (2007, p.483), similarly, notes the difficulty of bending the rules of 'being an academic' for students and supervisors alike: students must deal with their supervisors acting as boundary 'gatekeepers'; while academics must overcome their embeddedness in institutional historicity. Consideration is also given in the papers to where advocative behaviour reflects the engagement of coordinated action: Petersen (2007), for example, documents a supervisee deliberately aligning his research motives with those of the field's 'founding fathers', as a means of re-negotiating particular academic bounds established by his supervisor (p.484).

One issue centrally highlighted by Mahon (2017) is mutuality in approaches to interpreting and responding to practice problems (cf. engagement of shared responsibility). Mahon remarks that their study was designed to support 'the cogeneration of knowledge' about institutional academic practice; but they subsequently acknowledge that 'I was creating uneven levels of involvement, participation, and influence over the processes and outcomes' (p.82). Relational agency therefore resonates with a point of reflective critique by the author of their own study:

Looking at the situation retrospectively, I wonder what possibilities empirically and relationally - might have been afforded by making the ethnographic and self-study dimensions more collaborative. (p.82)

Overall, these papers laudably emphasise common knowledge and relational agency issues, while largely overlooking relational expertise. From our perspective, their analyses of common knowledge would benefit from more consideration of the knowledge of intelligible expression-thereby recognising practitioners' capacity to 'calibrate' their 'specialist responses' as they work on complex problems (cf. Edwards, 2017, p.11). Regarding relational expertise, we suggest that examining subjects' capacity to align motives would support a more particularised understanding of the fluid expertise necessary for achieving change in academic identity. The papers, as discussed, already recognise the value in engaging flexible responses when taking action and the consequences resulting from failure to engage shared responsibility. Better understanding the corresponding development of 
expertise would enable deeper understanding of what drives those particular observations.

\section{Concluding comments}

Let us take stock. Having outlined our relational working framework, our immediate aim was to demonstrate its potential for usefully re-interpreting previously published studies of boundary-working in higher education.

The preceding section has, in our view, addressed that aim convincingly. Using the framework to re-analyse papers examining enhanced leadership practices, for example, underscores positive existing recognition of how leadership is embedded in networks, and the importance of leaders reflecting on their own values; while also critiquing an underappreciation of actual objects of activity (the concrete problems leaders are motivated to address), the analytical occlusion of how different stakeholders perceive those objects, and a failure to understand how 'leadership' gets embedded in other subjects' practices. Similarly, our examination of research on producing societal knowledge accentuates the beneficial recognition of the time required to contextualise motives and the usefulness of a 'mutuality' work ethic; while pinpointing the analytical occlusion of how potential stakeholders are identified and recruited into collaboration, how subjects make themselves understood, and how collaborators deviate from routines in ways that serve to further develop practice.

Our critique of research on industry collaboration, meanwhile, applauds existing recognition that developing expertise is deeply entwined with attempts to find solutions to complex problems, yet points out that conceptualising expertise in ways analytically divorced from contingent action and subjects' construction of joint knowledge is problematic. Doing so, among other things, serves to elide the isolation of particular stakeholders, or how reciprocity might be built to overcome parallel working. Finally, our examination of research on intra-institutional boundaries concurs with analysis of how shared understanding develops within unfolding action; yet highlights a failure to grapple with the mechanisms by which subjects strive to 
overcome manifestations of the power asymmetries, and to make their knowledge understandable by others.

We reiterate that our argument is not that relational working is normatively 'better' than the existing frameworks used in the various papers. We simply contend that, for each cluster, the relational working framework can demonstrably be used to meaningfully interrogate and challenge existing research analysis, to suggest different and useful interpretations of phenomena, and to indicate plausible future avenues of investigation. Those are hallmarks, we suggest, of a useful theoretical framework (cf. Bligh and Flood, 2017).

Yet, early in the chapter, we set for ourselves an additional, more ambitious intellectual task: to resource the emergence of a different narrative to the boundarycrossing agenda. How might the act of analysing disparate scholarship using the relational working framework help us tease out new connections between presently fragmented areas of enquiry? What might be the benefits of an alternative relational working agenda for higher education research?

In our view, the preceding analysis hints at four potential benefits.

Firstly, such a research agenda would provide an opportunity to draw out common threads of insight, building on instances where scholars already strive towards ostensibly similar concrete aims under disparate circumstances. Our analyses of common knowledge, for example, highlights that most of the papers (except those in the industry collaboration cluster) foreground the knowledge of purposes-subjects' understanding of how others interpret and elaborate problems. Yet that is achieved in very different ways: such as constructing a common 'cause' (Prysor and Henley, 2018), cultivating a culture of 'questioning' (Penuel et al., 2015), or deliberately legitimating the expression of 'articulations', 'desires' and 'bodies' (Petersen, 2007, p.479). Plausibly, both the underlying practices and attendant analytical understandings in these different cases would be of mutual interest to researchers whose work is presently unconnected (fragmented, respectively, across scholarship devoted to investigating university leadership, the production of societal knowledge and relations between PhD students and supervisors). Similar observations could be 
made regarding the manner in which many papers differently strive to understand the relational expertise feature we have called the capacity to interconnect expertise, and the relational agency feature the engagement of shared responsibility. A relational working agenda might serve to nurture new forms of dialogue between these existing, and intuitively commensurate, avenues of investigation.

Secondly, a relational working agenda might bring into relief instances where researchers emphasise component aspects of what might become newly recognised as related issues. Consider our analyses, across the clusters, of the different core concepts of relational working. Relational expertise, for example, is relatively foregrounded by those papers focussed on producing societal knowledge and collaborating with industry, with each emphasising the importance of the capacity to contextualise motives (i.e., how subjects relate their common knowledge to the joint problem). Yet papers focussed on producing societal knowledge emphasise much more strongly the capacity to interconnect expertise (how subjects recognise the values of different participants' expertise to aspects of the problem), while those focussed on collaborating with industry more convincingly advocate the capacity to align motives (jointly re-interpreting the problem in light of participants' differing motives). Juxtaposing, and reconsidering the reasons underlying, these differing points of emphasis might serve as a possible basis for ameliorating analytical blind spots; and, in turn, for addressing some persistently encountered empirical problems. Once again, other examples can also be found (for example, the papers focussing on producing societal knowledge and negotiating intra-institutional identities each focus productively on relational agency overall, while highlighting different features).

Thirdly, a relational working agenda might accentuate the necessity of viewing relational working holistically: as a coherent, mutually supportive constellation of practices. In our analysis of the cluster on collaborating with industry, for example, we highlighted analytical shortcomings attributable to a narrow fixation on relational expertise-occluding how the latter necessarily arises within a nexus also encompassing common knowledge and relational agency. Similar, albeit less pronounced, fixation issues can be found in the clusters leading in a changing environment (overlooking relational agency) and negotiating institutional identities 
(eliding relational expertise). The latter case highlights a pronounced opportunity for researchers interested in boundary working within institutions to learn from work on producing societal knowledge and collaborating with industry, though not all such exercises viewing of viewing relational working more holistically need be onedirectional.

Fourthly, there is an opportunity to connect higher education scholarship with work in other fields, including those bodies of research based on work in schools, Children's Services and healthcare that undergird Edwards' understanding of relational working. Where none of the clusters we analyse in this chapter, for example, satisfactorily analyses the issue of the knowledge of intelligible expression (a core feature of common knowledge), it seems unlikely that the underlying reason is that the issue is mysteriously less important for higher education compared with other research settings. On the contrary, the fact that successful relational working demands a distinct capacity to render expertise available and fluid across multiple contexts would seem particularly pertinent, given the current incentive structures for research 'impact' and 'excellence' in many higher education systems. Tracing the presence and/or absence of this feature would, we suggest, encourage a longerterm view of how relational working affords a legacy to participants who have newly been able to make their own expertise explicit and accessible. Once again, the example we highlight here is but one among many. Over time, and especially given the privileged status of higher education within society as a locus for collaborative knowledge production, there is reason to believe that higher education researchers might have much to contribute to discussions with those engaged in studying relational working in other practice settings.

\section{References}

Algers, A., Lindström, B. and Svensson, L. (2016). Work-based learning through negotiated projects: Exploring learning at the boundary. Higher Education, Skills and Work-Based Learning, 6(1), 2-19. 
Bligh, B. (2019). Physical learning spaces and teaching in the blended learning landscape. In M. Peters (Ed.), Encyclopedia of Teacher Education. Heidelberg: SpringerNature.

Bligh, B., and Flood, M. (2017). Activity theory in empirical higher education research: choices, uses and values. Tertiary Education and Management, 23(2), 125-152.

Bok, D.C. (1982). Beyond the Ivory Tower: Social responsibilities of the modern university. Cambridge, MA: Harvard University Press.

Brown-Luthango, M. (2013). Community-University Engagement: The Philippi CityLab in Cape Town and the Challenge of Collaboration across Boundaries. Higher Education, 65, 309-324.

Edwards, A. (2005). Relational agency: learning to be a resourceful practitioner. International Journal of Educational Research, 43(3), 168-182.

Edwards, A. (2009). Relational agency in collaborations for the well-being of children and young people. Journal of Children's Services, 4(1), 33-43.

Edwards, A. (2010). Being an Expert Professional Practitioner: The relational turn in expertise. Dordrecht: Springer.

Edwards, A. (2011). Building common knowledge at the boundaries between professional practices: Relational agency and relational expertise in systems of distributed expertise. International Journal of Educational Research, 50(1), 33-39.

Edwards, A. (Ed.) (2017). Working Relationally In and Across Practices: A CulturalHistorical approach to collaboration. Cambridge: Cambridge University Press.

Edwards, A., Daniels, H., Gallagher, T., Leadbetter, J., \& Warmington, P. (2009). Improving inter-professional collaborations: Multi-agency working for children's wellbeing. London: Routledge. 
Enders, J. (2005). Border Crossings: Research Training, Knowledge Dissemination and the Transformation of Academic Work. Higher Education, 49(1), 119-133.

Esler, K.J., Downsborough, L., Roux, D.J., Blignaut, J., Milton, S., le Maitre, D. and de Wit, M.P. (2016). Interdisciplinary and multi-institutional higher learning: Reflecting on a South African case study investigating complex and dynamic environmental challenges. Current Opinion in Environmental Sustainability, 19, 7686.

Garraway, J. (2006). Creating Productive Interactions between Work and the Academy. Higher Education, 52(3), 447-464.

Georgalakis, J. (2017). Academics in ivory towers? It's time to change the record. Times Higher Education. Retrieved from:

https://www.timeshighereducation.com/blog/academics-ivory-towers-its-time-changerecord

Guile, D. (2011). Learning at the boundary: A commentary. International Journal of Education Research, 50 (1), 55-61.

Hasted, C. (2019). Humanities doctoral education for a relational future: A Change Laboratory research intervention. Ph.D. thesis, Lancaster University.

Hemmert, M. (2017). Knowledge acquisition by university researchers through company collaborations: Evidence from South Korea. Science and Public Policy, 44(2), 199-210.

Hopwood, N., (2017). Expertise, Learning and Agency in Partnership Practices in Services for Families with Young Children. In A Edwards (Ed.), Working Relationally in and across Practices: A Cultural-Historical Approach to Collaboration (pp.25-42). Cambridge: Cambridge University Press. 
Leontyev, A.N. (2009). Activity and Consciousness. Pacifica, CA: Marxists Internet Archive. (Original work published 1977).

Mahon, K. (2017). Negotiating democratic relations in a doctoral project examining university conditions and pedagogical praxis. Educational Action Research, 25(1), 71-87.

Nowotny, H., Scott, P., and Gibbons, M. (2001). Re-thinking science: Knowledge and the public in an age of uncertainty. Cambridge: Polity Press.

Penuel, W.R., Allen, A., Coburn, C.E. and Farrell, C. (2015). Conceptualizing Research-Practice Partnerships as Joint Work at Boundaries. Journal of Education for Students Placed at Risk, 20(1), 182-197.

Petersen, E.B. (2007). Negotiating Academicity: Postgraduate research supervision as category boundary work. Studies in Higher Education, 32(4), 475-487.

Prysor, D., and Henley, A. (2018). Boundary spanning in higher education leadership: Identifying boundaries and practices in a British university. Studies in Higher Education, 43(12), 2210-2225.

Sewerin, T., and Holmberg, R. (2017). Contextualizing distributed leadership in higher education. Higher Education Research and Development, 36(6), 1280-1294.

Spelt, E.J., Biemans, H.J., Tobi, H., Luning, P.A., and Mulder, M. (2009). Teaching and learning in interdisciplinary higher education: A systematic review. Educational Psychology Review, 21(4), 365-378.

Teichler, U., 2000. New perspectives of the relationships between higher education and employment. Tertiary Education and Management, 6(2), 79-92.

Tight, M. (2019). Higher Education Research: The developing field. London: Bloomsbury Academic. 
Suggested citation (while in press)

Hasted, C., \& Bligh, B. (in press). Theorising practices of relational working across the boundaries of higher education. To appear in J. Huisman \& M. Tight (Eds.), Theory and Method in Higher Education Research, Volume 6. Bingley: Emerald. 